\title{
DERECHO Y POLÍTICAS AMBIENTALES EN EXTREMADURA (SEGUNDO SEMESTRE 2016)
}

\author{
PEDRo BRUfao CURIEL \\ Profesor Contratado Doctor de Derecho Administrativo \\ Universidad de Extremadura
}

La primera norma que comentamos tiene su relación con una polémica revisión de la normativa de caza, la gestión de las especies necrófagas y la eliminación de los restos de las piezas de caza mayor abatidas en los innumerables cotos y zonas de caza de la región por sus efectos en la transmisión de enfermedades veterinarias con el ganado doméstico.

Se trata del Decreto 149/2016, de 13 de septiembre, por el que se determinan medidas sanitarias de salvaguardia sobre los subproductos animales no destinados al consumo humano, los cadáveres y sus partes de piezas de caza mayor al objeto de controlar la tuberculosis bovina en la Comunidad Autónoma de Extremadura. Esta norma deriva de varias Directivas de la UE de los años setenta del siglo XX, por las cuales España ha de conseguir la erradicación de esta enfermedad, a pesar de las dificultades que entraña la existencia de miles de cabezas de ganado bovino, y caprino también, en fincas de régimen extensivo que son a su vez el hábitat de ungulados sobre los que se ejerce la caza.

Una de las herramientas básicas es el establecimiento de zonas de actuación, de acuerdo con La Ley 6/2015, de 24 de marzo, Agraria de Extremadura y la Ley 8/2003, de Sanidad Animal, la cual establece medidas de salvaguardia aplicables tanto a los animales domésticos como a los salvajes. A su vez, este Decreto se basa en el Reglamento 1069/2009 del Parlamento Europeo y del Consejo, de 21 de octubre de 2009, por el que se establecen las normas sanitarias aplicables a los subproductos animales y los productos derivados no destinados al consumo humano, que permite definir las condiciones especiales de subproductos animales no destinados a consumo humano de zonas sujetas a restricciones por la presencia de una enfermedad transmisible grave destinadas a prevenir su propagación a los animales, como es el caso de las piezas abatidas de caza mayor que suelen dejarse abandonadas en las fincas, muchas de las cuales se encuentran 
en zonas de "emergencia cinegética", siendo el caso conocido del Parque Nacional y la Reserva de la Biosfera de Monfragüe una de ellas, donde está previsto el descaste de un millar de ciervas, más jabalíes y corzos, hasta finales de año por ser transmisores de la tuberculosis bovina.

Este Decreto 149/2016 incluye la previsión de la eliminación de los restos de venados y otros animales abatidos mediante diversas técnicas según el tipo de residuo de que se trate, previéndose la alimentación de aves necrófagas y su destino en muladares o el traslado a una planta de tratamiento. Las cuestiones de objetividad propias de toda norma jurídica salen a la palestra cuando se distingue entre cotos privados y los cotos sociales o cotos públicos y los diferentes métodos de caza, máxime cuando el riesgo de transmisión de la enfermedad es una cuestión objetiva, científica, que no distingue entre quién sea el titular del coto y el método de caza de los animales salvajes, causa más que suficiente para dudar de la legalidad de esta disposición reglamentaria. Esta cuestión se ha visto agravada por la contestación a este Decreto por parte de usuarios de los cotos sociales y por haber empelado la lamentable y esperpéntica técnica de la "corrección de errores" en los diarios oficiales ${ }^{1}$ para alterar el contenido normativo sometido a información pública y al dictamen consultivo previo, a la legalidad en definitiva ${ }^{2}$. Esta división entre tipos de cotos no apareció en el borrador de norma sometido información pública, lo que afecta de lleno a la participación pública garantizada por el Convenio de Aarhus. En la versión publicada se recogían distintos tipos de medidas según la naturaleza pública o privada de los cotos y tras esta torticera corrección de errores han quedado excluidos los cotos sociales, causa evidente, injustificable e inexplicable de ilegalidad de la norma vigente, ya que la tuberculosis bovina no distingue entre los distintos titulares de los terrenos cinegéticos y entre los métodos de caza.

Esta situación ha de tener en cuenta las acciones puntuales como las que refleja la Resolución de 6 de junio de 2016, de la Dirección General de Medio Ambiente, por la que se declara emergencia cinegética, por motivos de protección del medio natural y sanidad animal en el territorio de la Comunidad Autónoma de Extremadura, así como la Orden de 7 de junio de 2016 General de Vedas de Caza para la temporada 2016/2017,

\footnotetext{
${ }^{1}$ GUARDIOLA, J. "Corrección de errores en diarios oficiales: Usos, abusos y responsabilidades”. Corts. Anuario de Derecho Parlamentario, núm., 20. 2008.

${ }^{2}$ En materia de caza, vis. la STSJ de Castilla-La Mancha 41/2011, Sala de lo Contencioso-Administrativo, Sede de Albacete, Sección 1 ${ }^{\text {a }}$, de 24 de enero de 2011, recaída, entre otros motivos ante la impugnación de una orden de vedas afectada por dicha corrección de errores.
} 
cuya característica principal es que desoye lo establecido respecto del arruí por la STS, de la Sala $3^{\text {a }}$ del Tribunal Supremo, que anula diversas normas del Real Decreto 630/2013, de 2 de agosto, que regula el Catálogo español de especies exóticas invasoras, pues establece un período de veda para esta especie incluida en este catálogo, medida de protección que carece de todo amparo jurídico. Esto último no es sino muestra o de las presiones que el sector cinegético ejerce sobre las Administraciones públicas, o de la falta del estudio y actualización permanente en cuestiones jurídicas de los poderes públicos, o de una voluntad de inaplicar las resoluciones judiciales, o de una suma total o parcial de estos motivos. En la misma, sorprende la acogida por parte de las autoridades de la Junta de Extremadura de las pretensiones de ciertos grupos vinculados a la pesca de especies invasoras como el siluro, la carpa o la perca negra americana con el fin de que se inejecute dicha sentencia del Tribunal Supremo, grave cuestión si hablamos de un Estado de Derecho ${ }^{3}$.

El Derecho de la Biodiversidad ha contado este semestre con múltiples novedades, en especial respecto de las especies protegidas. En efecto, se han publicado la Orden de 13 de abril de 2016 por la que se modifica la Orden de 25 de mayo de 2015 por la que se aprueba el Plan de Conservación del Hábitat del Buitre negro (Aegypius monachus), la Orden de 13 de abril de 2016 por la que se modifica la Orden de 25 de mayo de 2015 por la que se aprueba el Plan de Conservación del Hábitat del Águila perdicera (Hieraaetus fasciatus) y la Orden de 13 de abril de 2016 por la que se modifica la Orden de 25 de mayo de 2015 por la que se aprueba el Plan de Recuperación del Águila Imperial Ibérica (Aquila adalberti). Estas normas han encontrado no pocas resistencias de nuevo en ciertos sectores del mundo cinegético y el forestal, dadas las limitaciones obvias a su ejecución tanto territorial como temporalmente.

Sin embargo, destacamos la Orden de 5 de mayo de 2016 por la que se aprueba el Plan de Recuperación del Lince Ibérico (Lynx pardinus), cuyos elementos principales los resumimos en que divide el territorio de actuación entre zonas críticas, favorables y de importancia, para las cuales se prevén diversas actuaciones limitadoras de actividades y obras, como la caza y las pistas forestales, así como de fomento a través de la custodia

\footnotetext{
${ }^{3}$ BRUFAO CURIEL, P. "Las especies exóticas invasoras y el Derecho, con especial referencia a las especies acuáticas, la pesca recreativa y la acuicultura", Revista Catalana de Derecho Ambiental, vol. 3, núm. 1. 2012.
} 
del territorio para su reintroducción. Por otra parte, incluye las pautas de actuación ante el hallazgo de ejemplares de linces muertos, heridos o enfermos.

Otra novedad a subrayar es la declaración como especies en peligro de extinción en Extremadura del sisón (Tetrax tetrax) y del milano real (Milvus milvus) en virtud de la aprobación del Decreto 74/2016, de 7 de junio, por el que se modifica el Decreto 37/2001, de 6 de marzo, por el que se regula el Catálogo Regional de Especies Amenazadas.

Acerca de la gestión de espacios naturales, sobresale el Decreto 51/2016, de 26 de abril, por el que se declara el Área Privada de Interés Ecológico "Valdepajares del Tajo", en el municipio de Peraleda de la Mata (Cáceres), cuyas más de 250 hectáreas de dehesa se verán comprometidas en proyectos de mejora del hábitat y de regulación de la actividad ganadera y cinegética.

Las actividades de custodia del territorio y de fomento de la protección de los espacios naturales se han visto modificadas por la aprobación del Decreto 129/2016, de 2 de agosto, por el que se establecen las bases reguladoras de la concesión de ayudas para el desarrollo sostenible en Áreas Protegidas, en zonas de reproducción de especies protegidas o en hábitat importante. Destaca lo prolijo de su articulado respecto de los beneficiarios de una gran serie de actividades que aquí se recogen a lo largo de sus más de 150 páginas.

La organización de los espacios naturales protegidos ha sufrido diversas modificaciones, aprobadas por el Decreto 75/2016, de 7 de junio, por el que se modifica el la organización y funcionamiento del Parque Nacional de Monfragüe y el Decreto 209/2009, de 4 de septiembre, por el que se regula la organización y funcionamiento de la Reserva de la Biosfera de Monfragüe, gracias al cual entran como miembros representantes de la Guardia Civil, empresas hidroeléctricas y organizaciones agrarias. Por otra parte, se ha aprobado el Decreto 142/2016, de 6 de septiembre, que modifica la Junta Rectora de la Zona Especial de Conservación (ZEC) "Sierra de San Pedro", así como el Decreto 143/2016, de 6 de septiembre, por el que se modifica el Decreto 138/2006, de 25 de julio, por el que se regula la Junta Rectora del Parque Natural del Tajo Internacional. Su fin es dar representación a los intereses turísticos de estas comarcas en las que se encuentran dichos espacios protegidos. 